\title{
ANALISIS KONDISI KEUANGAN MENGGUNAKAN METODE ZA VGREN PADA CV GREN TROPICAL PERIODE 2015-2017
}

\author{
Amalia Faradilah Suhendi ${ }^{1}$, Acep Samsudin ${ }^{2}$, Faizal Mulia $\mathbf{Z}^{3}$ \\ Program Studi Administrasi Bisnis Universitas Muhammadiyah Sukabumi ${ }^{1,2,3}$ \\ E-mail : amaliafaradilah27@gmail.com_1‥chevysy_77@yahoo.2, \\ faizal_88@ummi.ac.id ${ }^{3}$
}

\begin{abstract}
This study aims to determine how the company's financial condition on CV. Green Tropical during the period 2015-2017 using the Zavgren method. Company data is obtained from the company's financial statements. The data analysis technique used is the Zavgren method.

The results of this study are that in 2016 the value $(\mathrm{Pi})$ is relatively high and tends to increase. Increasing the value $(\mathrm{Pi})$ is influenced by the increase in the TURN variable which has a constant +0.11 and in 2017 the value $(\mathrm{Pi})$ returns to decrease. The decrease in value $(\mathrm{Pi})$ is influenced by a decrease in the CASH variable which has a constant -10.78 and a decrease in the TURN variable which has a constant +0.11 . the improvement in the company's financial condition improved due to the positive amount of working capital + fixed assets of the company and was triggered by the increasing number of sales which caused a decrease in the TURN ratio. The company's financial condition calculated using the Zavgren method shows that the overall financial condition of the company during the 2015-2017 period is included in the fluctuating critical category which means it can be said that the company's financial condition shows that the company's financial condition for the period 2015-2017 is stable.
\end{abstract}

Keywords: bankruptcy, Zavgren

\begin{abstract}
ABSTRAK
Penelitian ini bertujuan untuk mengetahui bagaimana kondisi keuangan perusahaan pada CV. Green Tropical selama periode 2015-2017 dengan mengunakan metode Zavgren. Data perusahaaan diperoleh dari laporan keuangan perusahaan. Teknik analisis data yang digunakan adalah metode Zavgren.

Hasil dari penelitian ini adalah pada tahun 2016 nilai (Pi) relatif tinggi dan cenderung meningkat. Meningkatnya nilai (Pi) dipengaruhi oleh meningkatnya variabel TURN yang memiliki konstanta +0.11 dan pada tahun 2017 nilai (Pi) kembali menurun. Menurunnya nilai (Pi) dipengaruhi oleh menurunnya variabel CASH yang memiliki konstanta -10.78 dan menurunnya variabel TURN yang memiliki konstanta +0.11 . peningkatan kondisi keuangan perusahaan menjadi membaik dikarenakan jumlah modal kerja + aktiva tetap perusahaan bernilai positif dan dipicu oleh jumlah penjualan yang meningkat yang menyebabkan menurunnya rasio TURN. kondisi keuangan perusahaan yang dihitung menggunakan metode Zavgren menunjukan bahwa kondisi keuangan perusahaan secara keseluruhan selama periode 2015-2017 termasuk dalam kategori kritis yang bersifat fluktuaktif yang berarti dapat dikatakan bahwa kondisi keuangan perusahaan menunjukan bahwa kondisi keuangan perusahaan selama periode 2015-2017 dalam keadaan stabil.
\end{abstract}

Kata Kunci: kebangkrutan, Zavgren. 


\section{PENDAHULUAN}

Dunia perekonomian menjadi penyebab suatu perusahaan bersaing dengan ketat. Suatu perusahaan dituntut untuk memperkuat diri agar bisa menghadapi perusahaan lain. Perusahaan mengelola keuangan dengan cara menerapkan adanya manajemen dan faktor yang mempengaruhi suatu kinerja perusahaan adalah dengan adanya perencanan keuangan yang baik, kelemahan dan kekuatan berkaitan dengan perusahaan. Perusahaan yang sudah lama beroperasi jangka panjang banyak yang membubarkan diri atau mengalami kebangkrutan karena mengalami kegagalan dalam menjalankan perusahaan. Perusahaan perlu menganalisis kondisi keuangan untuk dapat mengidentifikasi tanda-tanda awal suatu kebangkrutan. Semakin baik pihak manajemen mengetahui tanda-tanda awal kebangkrutan agar bisa mengambil strategi untuk memperbaiki kondisi keuangan dengan menggunkan metode zavgren. Menurut Stickney (2009) metode zavgren adalah "Zavgren mengembangkan model prediksi kebangkrutan dengan analisis logit. Yang menghasilkan probabilitas kemungkinan kebangkrutan. Zavgren menggunakan model ini pada 45 perusahaan yang sudah bangkrut dan tidak bangkrut. Model ni menggunakan rasio aktivitas, rasio solvabilitas, rasio likuiditas dan rasio profitabiltas. Selain kelompok rasio tersebut, model zavgren juga menggunakan dan memperhitungkan rasio piutang terhadap persediaan."

Laporankeuangan menggambarkan kondisi suatu perusahaan dan perkembangan keuangan yang merupakan salah satu bentuk informasi perusahaan. Fungsi laporan keuangan untuk menilai kinerja manajemen dalam mengelola sumber daya yang dimiliki sehingga perusahaan isa mempertahankan 
kelangsungan hidup dan menghindari kebangkrutan. Resiko kebangkrutan suatu perusahaan dapat diukur dan dilihat melalui laporan keuangan.

Perlambatan ekonomi menekan kinerja sejumlah industri tak terkecuali dibidang ekspor dan impor. profitabilitas perusahaan menururn karena melemahnya daya beli dan fluktuatif nilai tukar rupiah.

Tujuan dari penelitian ini adalah untuk mengetahui kondisi keuangan perusahaan menggunakan metode zavgren.

Berdasarkan uraian diatas maka penulis tertarik untuk melakukan penelitian dengan judul "Analisis kondisi keuangan menggunakan metode zavgren pada CV.Green Tropical periode 2013-2015"

Kajian Pustaka Menurut munawir (2010:5) laporan keuangan adalah “dua daftar yang disusun oleh akuntan pada akhir periode untuk suatu perusahaan. Kedua daftar itu adalah daftar neraca atau daftar posisi keuangan dan daftar pendapatan atau daftar rugi-laba. Pada waktu akhir-akhir ini sudah menjadi kebiasaan bagi perseroan-perseroan untuk menambahkan daftar ketiga yaitu daftar surplus atau daftar laba yang tak dibagikan (laba yang ditahan).”

Menurut munawir (2010:7) jenis -jenis laporan keuangan adalah "pada umumnya terdiri dari neraca dan perhitungan rugi laba serta laporan perubahan modal, dimana neraca menunjukan atau menggambarkan jumlah aktiva, hutang dan modal dari suatu perusahaan pada tanggal tertentu, sedangkan perhitungan (laporan) laba rugi memperlihatkan hasil-hasil yang telah dicapai oleh perusahaan serta biaya yang terjadi selama periode tertentu dan laporan perubahan modal 
menunjukan sumber dan penggunaan atau alasan-alasan yang menyebabkan perubahan modal perusahaan."

Dari definisi-definisi diatas yang dikemukakan oleh para ahli maka dapat disimpulkan bahwa laporan keuangan adalah suatu ringkasan dari transaksitransaksi keuangan pada periode tertentu dan menggambarkan kondisi keuangan perushaan sebagai gambaran kinerja keuangan pada perusahaan.

Menurut Irham Fahmi (2012:22) Kinerja keuangan perusahaan adalah "gambaran dari pencapaian keberhasilan perusahaan dapat diartikan sebagai hasil yang telah dicapai atas berbagai aktivitas yang telah dilakukan. Dapat dijelaskan bahwa kinerja keuangan perusahaan adalah suatu analisis untuk mengetahui sejauh mana perusahaan melaksanakan dan melakukan aturan pelaksanaan keuangan secara baik dan benar."

Menurut Lesmana (2003:174) Kebangkrutan adalah "ketidakpastian mengenai kemampuan atas suatu perusahaan untuk melanjutkan kegiatan operasionalnya jika kondisi keuangan yang dimiliki mengalami penurunan.”

Menurut (Stickney, 2009) metode ini adalah "bagaimana kondisi keuangan suatu perusahaan, karena suatu kondisi keuangan bisa berdampak pada kelangsungan hidup perusahaan dan menjadi salah satu faktor kebangkrutan suatu perusahaan. Metode ini disebut dengan metode zavgren. Zavgren mengembangkan model prediksi kebangkrutan engan ananlisi logit. Yang menghasilkan probabilitas kemungkinan kebangkrutan. Zavgren menggunakan model ini pada 45 perusahaan yang sudah bangkrut dan tidak bangkrut. Model ni menggunakan rasio aktivitas, 
rasio solvabilitas, rasio likuiditas dan rasio profitabiltas. Selain kelompok rasio tersebut, model zavgren juga menggunakan dan memperhitungkan rasio piutang terhadap persediaan."

\section{METODE PENELITIAN}

Metode yang digunakan untuk mendapat jawaban dari masalah adalah metode penelitian dekriptif kuantitatif. Menurut Punaji Setyosari (2010:89) penelitian deskriptif adalah: "penelitian yang bertujuan untuk menjelaskan atau mendeskripsikan suatu keadaan, peristiwa, objek apakah orang atau segala sesuatu yang terkait dengan variabel-variabel yang bisa dijelaskan baik dengan angkaangka maupun kata-kata."

Sedangkan menurut Suharismi Arikunto (2013:27) penelitian kuantitatif adalah "penelitian kuantitatif sesuai dengan namanya, banyak dituntut menggunakan angka, mulai dari pengumpulan data, penafsiran data tersebut serta penampilan hasilnya."

Menurut pendapat para ahli diatas maka dapat disimpulkan bahwa penelitian deskriptif kuantitatif adalah digunakan untuk mendeskripsikan suatu kejadian atau perisitiwa dalam bentuk angka yang bermakna.Teknik Pengumpulan Data: Data primer adalah sumber data yang langsung memberikan data kepada pengumpul data (Sugiyono 2010: 137). Dalam data primer ada teknik pengumpulan data melalu observasi, yaitu merupakan proses pengumpulan data dengan cara terjun langsung ke lapangan dan melalui proses mengamati dan mengingat. Dalam penelitian ini dari segi observasi dan pengumpulan data adalah observasi 
nonpartisipan, yaitu peneliti tidak terlibat langsung dalam kegiatan dan hanya sebagai pengamat independen. Saat pengambilan data hanya mencatat dan mengamati obyek penelitian dan menyimpulkan.

Obyek penelitian ini adalah laporan keuangan suatu perusahaan pada CV. Green Tropical. Adapun data yang diperoleh berupa laporan keuangan pada periode 2015 sampai dengan 2017. Penelitian dilakukan pada semester ganjil bulan oktober 2018 sampai dengan maret 2019. Variabel yang diteliti adalah metode zavgren. Zavgren dihitung melalui empat langkah. Menghitung tujuh rasio keuangan, setiap rasio dikalikan dengan koefisien khusus, hasil dijumlahkan bersamaan dan menghitung probabilitas kebangkrutan.

Teknik analisis data yang digunakan dalam penelitian ini ada menggunakan beberapa perhitungan. Adalah sebagai berikut:

Mengitung serangkaian tujuh rasio

\section{Menghitung rasio INV}

$$
\frac{\text { rata-rata penjualan }}{\text { penjualan }}
$$

\section{Menghitung rasio REC}

$$
\frac{\text { rata-rata piutang }}{\text { rata-rata persediaan }}
$$

\section{Menghitung rasio $\mathrm{CASH}$}

kas + Surat berharga 


\section{Menghitung rasio QUICK}

$\frac{\text { Quick assets }}{\text { Hutang Lancar }}$

Menghitung rasio ROI

$\frac{\text { laba operasi bersih }}{\text { total aktiva-hutang lancar }}$

\section{Menghitung rasio DEBT}

$\frac{\text { Hutang jangka panjang }}{\text { Total Aktiva-Hutang lancar }}$

\section{Menghitung rasio TURN}

$\frac{\text { penjualan }}{\text { modal kerja+aktiva tetap }}$

Setiap rasio dikalikan dengan koefisien khusus

$$
\begin{aligned}
& \text { Y }=0,23883-0,108 \text { (INV) }-1,583(\text { REC) }-10,78(\text { CASH })+3,074 \\
& (\text { QUICK })+0,486(\text { ROI })-4,35(\text { DEBT })+0,11(\text { TURN })
\end{aligned}
$$

Hasil atau nilai yang didapat lalu dijumlahkan secara bersaman (Y).Probabilitas kebangkrutan perusahaan dikalkulasi dengan fungsi probabilitas logit.

\section{Rumus zavgren logit adalah sebagai berikut:}

$$
P_{i}=\frac{1}{1+e^{y}}
$$

Ket :

$$
\begin{aligned}
& \boldsymbol{P}_{\boldsymbol{i}}: \text { Probabilitas kebangkrutan } \\
& e: 2.718282 \text { (Bilangan alam) } \\
& \boldsymbol{y}: \text { Fungsi Multivarian }
\end{aligned}
$$




\section{HASIL DAN PEMBAHASAN}

Berikut hasil dari perhitungan menggunakan metode Zavgren :

Tabel 1. Hasil perhitungan tujuh rasio keuangan

\begin{tabular}{llll}
\hline \multicolumn{1}{c}{ VARIABEL } & \multicolumn{1}{c}{2015} & \multicolumn{1}{c}{2016} & 2017 \\
\hline INV & 0.5 & 0.5 & 0.5 \\
\hline REC & 16.942 .652 & 22.093 .750 & 24.097 .875 \\
\hline CASH & 0.813371606 & 0.865619393 & 0.825599668 \\
\hline QUICK & 307.974356 & 260.327869 & 310.1339003 \\
\hline ROI & & & 0.51082891 \\
\hline DEBT & 4.254340507 & 0.509129448 & 591.779 .428 \\
\hline TURN & 1.20882882 & 2.503826219 & 1.947990626
\end{tabular}

Sumber: Data diolah

Tabel 2. Hasil perhitungan y

\begin{tabular}{llll}
\hline \multicolumn{1}{c}{ VARIABEL } & \multicolumn{1}{c}{2015} & \multicolumn{1}{c}{2016} & \multicolumn{1}{c}{2017} \\
\hline INV & 0.054 & 0.054 & 0.054 \\
\hline REC & 26.820 .218 & 34.974 .406 & 38146936.13 \\
\hline CASH & 8.768146 & 9.331377 & 8.899964426 \\
\hline QUICK & 946.713169 & 800.247870 & 953.3516096 \\
\hline ROI & 0.123609 & 0.247437 & 0.24826285 \\
\hline DEBT & 2.130 .321 .233 & 2.065 .762 .482 & 2.574240512 \\
\hline TURN & 0.132971 & 0.275421 & 0.214278696 \\
\hline Y & -1.219 .196 .428 & -1.309 .820 .395 & $-1.667 .935,803$
\end{tabular}

Sumber: Data Diolah

Tabel 3. Hasil perhitungan menggunakan metode Zavgren

\begin{tabular}{llll}
\hline VARIABEL & 2015 & 2016 & 2017 \\
\hline
\end{tabular}




\begin{tabular}{llll}
\hline ZAVGREN & 0.228077895 & 0.432934094 & 0.158699584
\end{tabular}

$$
P_{i}=\frac{1}{1+e^{y}}
$$

\begin{tabular}{llll}
\hline KATEGORI & KRITIS & KRITIS & KRITIS \\
\hline
\end{tabular}

Sumber: Data diolah

Dari hasil yang telah dianalisis menggunakan metode Zavgren sebagaimana yang terlihat pada tabel diatas selama periode 2015-2017 dikategorikan dalam masa kritis dan dapat diketahui pada keuangan perusahaan selama periode 2015-2017 bersifat fluktuaktif. Apabila dilihat secara umum kondisi keuangan perusahaan bisa dikatakan stabil. Kondisi terburuk terjadi pada tahun 2016 dimana nilai (Pi) relatif paling tinggi dibandingkan pada tahun 2015 dan 2017. Pada tahun 2016 nilai (Pi) cenderung meningkat yang dalam hal ini dapat diartikan kondisi keuangan memburuk. Pada tahun 2016 dikatakan dalam kondisi terburuk dikarenakan nilai (Pi) yang cukup tinggi dengan nilai (Pi) sebesar (0.432934095) yang mendekati nilai 1 dan dapat diartikan kondisi keuangan pada tahun 2016 memiliki potensi kebangkrutan perusahaan yang tinggi. Yang menyebabkan nilai (Pi) tinggi pada tahun 2016 adalah secara umum meningkatnya nilai (Pi) yang dipengaruhi oleh variabel TURN yang meningkat dan memiliki konstanta +0.11 . namun meskipun pada tahun 2016 adalah kondisi keuangan perusahaan dengan nilai (Pi) yang relatif tinggi akan tetapi pada tahun 2017 adalah kondisi keuangan yang dimana masih dalam kategori kritis dan bisa dikatakan membaik karena pada tahun 2017 ini nilai (Pi) cenderung menurun. Menurunnya nilai (Pi) dapat diartikan bahwa pada kondisi keuangan membaik dan kondisi keuangan perusahaan dari tahun 2015 sampai dengan 2017 dapat diartikan dalam keadaan kondisi keuangan perusahaan yang stabil. Meningkatnya kondisi keuangan perusahaan dipengaruhi oleh variabel 
CASH yang menurun dan memiliki konstanta -10.78 dan menurunnya variabel TURN yang memiliki konstanta +0.11 . peningkatan kondisi keuangan perusahaan menjadi membaik dikarenakan jumlah modal kerja + aktiva tetap perusahaan bernilai positif dan dipicu oleh jumlah penjualan yang meningkat yang menyebabkan menurunnya rasio TURN. Peningkatan jumlah modal kerja + aktiva tetapnya dari tahun 2015 sebesar Rp.544.957.019 menjadi sebesar Rp.643.349.220 pada tahun 2017. Pada tahun 2016 kondisi keuangan memburuk dan kembali membaik pada tahun 2017. Dilihat dari kondisi keuangan yang membaik dan mulai stabil maka perusahaan bisa mempertahankan kondisi keuangannya.

\section{SIMPULAN DAN SARAN}

Berdasarkan hasil penelitian yang telah dilakukan pada perusahaan CV. Green Tropical pada periode 2015 sampai dengan 2017 maka dapat disimpulkan kondisi keuangan pada perusahaan CV. Green Tropical dikategorikan dalam kriteria kritis. Namun meskipun dikategorikan dalam kriteria kritis, kondisi keuangan perusahaan dapat dikatakan stabil dan membaik karena pada tahun 2016 kondisi keuangan perusahaan memburuk dan kembali membaik pada tahun 2017. Berdasarkan kesimpulan diatas maka akan diajukan saran yang bisa dipertimbangkan oleh pihak perusahaan.

Perusahaan dapat meningkatkan penjualan untuk menghasilkan kas dan juga laba bersih yang jauh lebih baik lagi. Perusahaan dapat mengefesiensikan beban yang ada dalam perusahaan. Tetapi kendala perusahaan menunjukan permasalahan seperti naik turunnya harga dollar dan penunggakan pembayaran dari pihak 
customer serta keterbatasan bahan baku yang dapat mempengaruhi laba bersih dan pendapatan keuangan perusahaan. Maka dari itu pihak perusahaan bisa melakukan disersifikasi usaha serta perusahaan dapat mengurangi hutang usaha pada keterlambatan pembayaran yang berada dipihak customer.

\section{REFERENSI}

Agustina, Yeni dan Rahmawati. (2010). Kebangkrutan Perusahaan Menggunakan Model Altman Dan Zavgren Pada Perusahaan Food And Beverage. Journal The Winners volume 11 nomor 1.

Arikunto, S. (2013). Prosedur Penelitian: Suatu Pendekatan Praktik. Jakarta: Rineka Cipta.

Dewi, F.N. 2015. Prediksi Kebangkrutan dengan menggunakan Model Zavgren (Logit) (Studi Kasus pada Perusahaan Tekstil dan Garmen yang terdaftar di Bursa Efek Indonesia). Jurnal Ilmiah Mahasiswa FEB Universitas Brawijaya. Vol 4, No. 2, Semester Genap 2015/2016.

Fahmi, I. 2012. Analisis Laporan Keuangan. Bandung: Alfabeta.

Kasmir. 2013. Analisis Laporan Keuangan. Rajawali Pers : Jakarta.

Kasmir. 2015. Analisis Laporan Keuangan. Rajawali Pers : Jakarta.

Lugisman. 2009. Analisis Laporan Keuangan Dengan Mengunakan Metode Zavgren Logit Model Pada PT. Indocement Tunggal Prakasa dari periode 1994-2004. Journal The Winers Tahun 2010

Munawir, S. 2010. Analisis Laporan Keuangan. Edisi Empat. Yogyakarta: Liberty.

Setiawan. 2004. Identifikasi Kondisi Keuangan Menggunakan Metode Altman Zscore dan Metode Zavgren Pada Perusahaan Automotive And Alied Products Yang Terdaftar di BEJ Dari Periode 1999-2001. Journal The Winners Tahun 2008.

Setyosari, Punaji. 2010. Metode Penelitian dan Pengembangan. Jakarta: Kencana.

Sugiyono. 2010. Metode Penelitian Kuantitatif, Kualitatif dan R\&D. Bandung: Alfabeta.

Sugiyono. 2013. Metode Penelitian Kuantitatif, Kualitatif dan R\&D. Bandung: Alfabeta. 
Amalia Faradilah Suhendi, Acep Samsudin, dan Faizal Mulia Z. Analisis Kondisi Keuangan........

Sugiyono. 2015. Metode Penelitian Bisnis. Bandung: Alfabeta.

Zavgren, Christine V; Friedman, George E. (2009). Are Bankruptcy Prediction model Worthwhile? An Application In Securities Analysis. Management International Review. 28.1; ABI/ INFORM Global pg.34. 